\title{
Effects of pasture type and level of concentrate supplementation on quality and fatty acid profile of lamb meat
}

\author{
J.A. Rossatti ${ }^{1}$, F.M. Vargas Junior ${ }^{1}$, M. Retore ${ }^{2}$, G.D.V. Britez ${ }^{1}$, M.C. Silva ${ }^{1}$, T. \\ Fernandes $^{1 \#}$, A.R.M. Fernandes ${ }^{1}$ \& M. Mele $^{3}$ \\ ${ }^{1}$ Post-graduate Program in Animal Science, Federal University of Grande Dourados (UFGD), Dourados, Rodovia \\ Dourados-Itahum, km 12 -Unidade II, Caixa Postal: 322, CEP 79825-070, Mato Grosso do Sul, Brazil; \\ ${ }^{2}$ Embrapa Western-Region Agriculture, Dourados, BR 163, km 253,6. Trecho Dourados, Caarapó, Caixa Postal: \\ 449, CEP 79804-970, Mato Grosso do Sul, Brazil; \\ ${ }^{3}$ Department of Agricultural, Food and Agri-environmental Sciences, University of Pisa, Italy
}

(Received 27 February 2019; Accepted 16 October 2019; First published online 1 January 2020)

Copyright resides with the authors in terms of the Creative Commons Attribution 4.0 South African License.

See: http://creativecommons.org/licenses/by/4.0/za

Condition of use: The user may copy, distribute, transmit and adapt the work, but must recognize the authors and the South African Journal of Animal Science.

\begin{abstract}
Objectives of this study were to evaluate effects of grazing tropical forage species and level of supplementation with grain on characteristics of lamb meat. Ninety-day-old lambs $(n=36)(22.54 \pm 2.72$ $\mathrm{kg}$ ) were randomly assigned to a $2 \times 3$ factorial arrangement of pasture types (Aruana and Marandu) and levels of concentrate supplementation $(0 \%, 1.5 \%$ and $3 \%$ of bodyweight). Water retention capacity, shear force, weight loss after cooking, $\mathrm{pH}$, colour, and intramuscular lipid content of the meat were evaluated. A panel of 145 consumers evaluated the appearance, flavour, fat flavour, odour, and softness of the meat and provided an overall assessment. Supplementation at 3\% of bodyweight reduced the luminosity of the meat. The appearance of meat from lambs that grazed Aruana grass was deemed preferable to that of meat from lambs that grazed Marandu grass. Total branched-chain fatty acids (BCFAs) were increased when grazing Marandu grass compared to Aruana grass. Lambs supplemented with concentrate had reduced BCFA/kg of meat and its content of both monounsaturated (MUFA) and polyunsaturated (PUFA) fatty acids were increased. Supplementation with concentrate at $1.5 \%$ and $3.0 \%$ of bodyweight increased $n-6$ PUFAs by $16.8 \%$ and $90.0 \%$, decreased $n-3$ PUFAs by $49.7 \%$ and $35.9 \%$, and thus increased the $n-6 / n-3$ ratio by $135.0 \%$ and $183.8 \%$, respectively. Lambs that were finished on grass without supplementation had a more healthful fatty acid profile and received better scores for flavour and global appreciation. To improve the quality of fatty acids in the meat, the pasture system is recommended.
\end{abstract}

Keywords: Brachiaria brizantha, lipid content, Longissimus thoracis et lumborum, Panicum maximum, sheep feeding

\#Corresponding author: fernandest.zootc@gmail.com

\section{Introduction}

Production of sheep meat depends on forage resources to produce quality animal protein (Sousa, 2007). Marandu grass is predominant in Brazil owing to its adaptation to different soils, ease of planting and management, and drought resistance (Faccin et al., 2014). Aruana grass is readily consumed by sheep and has a favourable nutritive profile. It is productive, has a high capacity of regrowth, and is recommended for sheep owing to its low height (Zanini et al., 2012; Vargas Junior et al., 2013).

Efficiency in sheep meat production can be improved with supplementation that ensures increased productivity compared with the traditionally developed extensive systems (Emerenciano Neto et al., 2011). Supplementation at appropriate levels can help satisfy nutritional requirements and allows the production of animals with carcass characteristics that meet consumers' expectations (Santos et al., 2009; Papi et al., 2011). It can also improve nutrient-use efficiency for maximal performance by grazing livestock (Turner et al., 2014).

There are significant differences in lamb consumption between countries and regions (Daszkiewicz et al., 2018). Variation in supply and relatively high prices of lamb meat limits consumption (Muela et al., 2010). Consumers appreciate the originality, specific sensory attributes, and traditional character of lamb meat 
(Muela et al., 2016). Meat quality from grass-fed lambs is perceived to be better than that from concentratefed lambs. However, moderate levels of supplementation with concentrates on pasture do not change the characteristics of lamb meat (Boughalmi et al., 2016).

Animal nutrition influences sheep meat in terms of its physical properties (Moreno et al., 2016), meat and fat colour (Joy et al., 2008), sensory aspects (Osório et al., 2009), and fatty acid (FA) profile (Alves et al., 2012). Consumers believe that meat colour is the most important indicator of meat quality (Neethling et al., 2017) and it is considered by them in deciding to purchase meat (Abdelrahman et al., 2018). Lipid composition of ruminant tissues is determined by lipid metabolism in the rumen (Alvez et al., 2013). Some isomers of conjugated linoleic acid, which is produced in the rumen, have important biological properties for human beings (Pariza et al., 2001).

It is pertinent to establish the effects of the concentrate to tropical forage ratio on lamb performance and carcass traits, especially the ability to produce carcasses that are deemed suitable according to commercial standards (Claffey et al., 2018). Given that the consumer of lamb meat is demanding, and that the quality of the meat depends on sources of nutrients provided to the animal, the objective of this study was to evaluate the effects of tropical forage species and the level of supplementation, with the focus on the physical characteristics, sensory aspects and fatty acid composition of lamb meat.

\section{Material and Methods}

All experimental protocols were approved by the Animal Experimentation Ethics Committee (CEUA) of the Federal University of Grande Dourados. The experiment was conducted at the Experimental Area of Embrapa Western-Region Agriculture, in Ponta Porã, Mato Grosso do Sul. The experimental area has the geographical coordinates $22^{\circ} 32^{\prime} 56^{\prime \prime} \mathrm{S} 55^{\circ} 38^{\prime} 56^{\prime \prime} \mathrm{W}$ and is at an altitude of $642 \mathrm{~m}$. The trial was run in summer during which time precipitation was $874 \mathrm{~mm}$ and with temperatures ranging from 18.6 to $29.0{ }^{\circ} \mathrm{C}$.

Thirty-six intact male Suffolk lambs, weaned at a mean of 90 days old and with initial average bodyweight (BW) of $22.54 \pm 2.72 \mathrm{~kg}$, were used in this study. A 1.23 ha area was divided into paddocks, measuring $32 \times 32 \mathrm{~m}$ each. The experiment was of a completely randomized design with a $2 \times 3$ factorial arrangement of two types of pasture (Panicum maximum (Aruana) and Brachiaria brizantha (Marandu)) and three levels of concentrate supplementation $(0 \%, 1.5 \%$ and $3 \%$ of $\mathrm{BW})$. There were two replications of paddock and three animals in each paddock for a total of 36 animals and 12 experimental units (paddocks). The animals grazed the available forage, estimated by leaf area as $5.39 \pm 0.79 \mathrm{~m}^{2} / \mathrm{m}^{2}$ for Aruana grass and $11.57 \pm 1.72 \mathrm{~m}^{2} / \mathrm{m}^{2}$ for Marandu grass, continuously. The supplementation consisted of ground soybean (33\%), corn (22\%) and oats (45\%), provided at 08:00 hours (Table 1). The animals were weighed every 14 days for adjustments in the amount of supplement. Mineral salt and water were offered ad libitum.

Table 1 Chemical composition of the dietary ingredients for lambs grazing either Aruana grass or Marandu grass and supplemented with concentrates

\begin{tabular}{lrrr}
\hline Nutrient & Aruana grass & Marandu grass & $\begin{array}{r}\text { Concentrate } \\
\text { supplement }\end{array}$ \\
\hline Dry matter (g/kg as fed) & $281.2 \pm 08.4$ & $315.0 \pm 09.6$ & 871.2 \\
Organic matter (g/kg of DM) & $922.4 \pm 08.4$ & $915.2 \pm 10.3$ & 947.5 \\
Crude protein (g/kg of DM) & $165.8 \pm 38.5$ & $51.7 \pm 13.6$ & 218.4 \\
Neutral detergent fibre (g/kg of DM) & $629.4 \pm 43.7$ & $652.7 \pm 62.3$ & 354.4 \\
Acid detergent fibre (g/kg of DM) & $298.5 \pm 42.4$ & $309.5 \pm 52.1$ & 82.9 \\
Ether extract (g/kg of DM) & $13.2 \pm 05.9$ & $11.8 \pm 03.2$ & 88.3 \\
Fatty acids (g/kg of fat) & & & $1.08 \pm 0.05$ \\
C 12:0 Lauric acid & $5.20 \pm 0.34$ & $5.05 \pm 0.25$ & $51.45 \pm 2.41$ \\
C 14:0 Myristic acid & $7.48 \pm 0.19$ & $7.85 \pm 0.19$ & $177.50 \pm 0.67$ \\
C 16:0 Palmitic acid & $300.25 \pm 0.99$ & $300.03 \pm 0.22$ & $3.18 \pm 0.22$ \\
C 16:1 Palmitoleic acid & $6.28 \pm 0.21$ & $6.28 \pm 0.21$ & $20.03 \pm 0.33$ \\
C 18:0 Stearic acid & $36.90 \pm 0.29$ & $36.85 \pm 0.24$ & $349.23 \pm 1.61$ \\
C 18:1 Vaccenic acid & $20.55 \pm 1.06$ & $37.33 \pm 3.62$ & $364.60 \pm 1.64$ \\
C 18:2 Linoleic acid & $150.40 \pm 0.39$ & $169.48 \pm 0.48$ & $18.15 \pm 0.25$ \\
C 18:3 $\alpha$ - and y-Linolenic acid & $362.68 \pm 0.68$ & $379.03 \pm 0.79$ & \\
\hline
\end{tabular}


The animals were slaughtered when they reached a body condition score between 2.5 and 3.0 on a scale of 1 - 5 (Pugh, 2004), or a maximum age of six months. Six animals were slaughtered on days 73, 77, 91, 98, 105, and 126 of the experiment. Before slaughter, the animals were fasted (solids) for 16 hours and weighed. Slaughter was consistent with the Regulation of Industrial and Sanitary Inspection of Products of Animal Origin (RIISPOA) (Brazil, 2000). Briefly, the lambs were stunned by electronarcosis (8 seconds of $220 \mathrm{~V}$ discharge), followed by the cutting of the jugular veins and carotid arteries, and subsequently eviscerated. After slaughter, the carcasses were stored at $4{ }^{\circ} \mathrm{C}$ for 24 hours. Subsequently, the Longissimus thoracis et lumborum (LM) muscles were removed and kept frozen until analysis.

Water-holding capacity (\%) was measured according to the method described by Hamm (1960). Shear force (SF) (kg) was determined for meat that had been cooked to a final internal temperature of $71{ }^{\circ} \mathrm{C}$ using a belt grill (TBG-60 Magigrill, MagiKitch'n Inc., Quakertown, PA, USA). After the steaks left the belt grill, they were held at room temperature, and a 1-cm thick, $5-\mathrm{cm}$ long slice was removed from the lateral end of each steak parallel to the muscle fibres and evaluated in accordance with Hopkins (2010) using a texture analyser (TA-XT2i, Texture Technologies Corp, Scarsdale, NY) with a Warner-Bratzler blade. Weight loss after cooking (\%) was estimated from the difference between the weights of raw and cooked samples. The $\mathrm{pH}$ was measured three times for each sample using a digital potentiometer with a penetration probe (Testo 205/206). Colour was evaluated after 30 minutes of exposure to air to allow the myoglobin to react with oxygen (Cañeque et al., 2000). Luminosity and the red and yellow intensity were determined with a CR-400 colorimeter and illuminant D65 at a viewing angle of $10^{\circ}$ and an aperture diameter of $8 \mathrm{~mm}$ (Konica Minolta Sensing Inc., Japan). The tone angle and the saturation index were calculated (CIE, 1978).

Meat samples were lyophilised $\left(-60^{\circ} \mathrm{C}\right.$ and $\left.2.0 \mathrm{hPa}\right)$ to a constant weight, using a lyophiliser (Edwards High Vacuum International, West Sussex, UK). To determine intramuscular lipid content, total lipids were extracted from lyophilized meat samples (ca. $3 \mathrm{~g}$ ) with a chloroform-methanol solution (Bligh \& Dyer, 1959). Fatty acid analyses were conducted as described by Sant'Ana et al. (2018).

Sensory analysis was carried out by a panel of 145 evaluators, consisting of 87 men and 58 women. The panellists ranged in age from less than 22 years (66\%), 22 - 30 years (26\%), 30 - 46 years (7\%), to over 46 years (1\%). The samples were roasted on a grill until their geometric centre reached a temperature of $70{ }^{\circ} \mathrm{C}$ (Rodrigues \& Teixeira, 2009). After a short period of cooling, sodium glutamate was applied to enhance the flavour, and the samples were identified with a code and cut into $2 \mathrm{~cm}$ cubes. The samples were served in plastic containers to evaluate their attributes with a hedonic scale adapted from 0 to 10 points, namely appearance ('not liked' to 'liked very much'), flavour (intense to mild), fat flavour (intense to mild), odour (strong to mild), softness (firm to soft), and provide an overall assessment ('not liked' to 'liked very much') (Rodrigues \& Teixeira, 2009). At the same time, the panellists were questioned about the possibility of purchasing the product and the price they would be willing to pay for it.

Physical properties of the meat, FA content and sensory data were analysed using PROC MIXED of SAS version 9.3 (SAS Institute Inc., Cary, NC USA). The model was:

$$
\mathrm{Y}_{\mathrm{ijk}}=\mu+\mathrm{G}_{\mathrm{i}}+\mathrm{S}_{\mathrm{j}}+\mathrm{GS}_{\mathrm{ij}}+d_{i j k}+\mathrm{e}_{\mathrm{ijk}}
$$

Where: $Y_{i j k}$ is an observation from the kth experimental unit, $\mu$ is the overall mean, $\mathrm{G}_{\mathrm{i}}$ is the effect of the variety of grass ( $i=$ Aruana, Marandu), $S_{j}$ is the effect of supplementation $(j=0 \%, 1.5 \%, 3.0 \%)$,

$\mathrm{GS}_{\mathrm{ij}}$ is the interaction effect of the ith variety of grass and the jth quantity of supplement, $d_{i j k}$ is the linear random effect of slaughter day, and $\mathrm{e}_{\mathrm{ijk}}$ is the experimental error.

Differences between means were assessed with the Bonferroni test, and statistical significance was established at $P \leq 0.05$.

Principal component analysis (PCA) was performed using STATISTICA 8.2 (TIBCO Software Inc., Palo Alto, CA, USA). For the PCA, the partial sums of FA were used as active data to create a vector of correlated variables, and individual FA was used as supplementary data, plotted in the graphic to observe the relationship between this variable and the sums of FA (Vicini et al., 2005). For PCA of the sensory aspects, the sensory variables were used as active data to create a vector of correlated variables, and instrumental indicators and partial sums of FA were used as supplementary data, plotted in the graphic to observe the relationship between sensory aspects and instrumental indicators, and partial sums of FA (Vicini et al., 2005). Only those variables with correlations to the factors that were greater than 0.5 are shown graphically. Discriminant analysis was used in an attempt to relate the sensory attributes and the six 
treatments in order to assign consumer perception to categories (treatments) based on the variancecovariance structure.

\section{Results}

The variety of grass had no detectable effect on the physical characteristics of the meat (Table 2). Luminosity values were greater for meat from lambs that did not receive supplementation compared with meat from animals supplemented at $3.0 \%$ of their BW. The intensity of yellow was greater in lambs fed with Marandu grass, and lowest in animals with fed concentrate at $1.5 \%$ of their BW. The differences in intensity of yellow resulted in low tone angle of lambs fed with $1.5 \%$ concentrate supplement. The intensity of red, the saturation index and the water retention capacity were unaffected by the treatments. There was interaction for SF in that meat from animals that were on Marandu grass pasture had lower SF when they received concentrate supplementation, while animals that were on Aruana grass pasture had higher SF when they received concentrate supplementation.

Table 2 Indicators of meat quality of the Longissimus thoracis et lumborum muscle of lambs that grazed Aruana or Marandu grass and were supplemented with concentrate at $0.0 \%, 1.5 \%$ or $3.0 \%$ of bodyweight

\begin{tabular}{|c|c|c|c|c|c|c|c|c|c|c|}
\hline \multirow{2}{*}{$\begin{array}{l}\text { Grass } \\
\text { Supplementation }\end{array}$} & \multicolumn{3}{|c|}{ Aruana } & \multicolumn{3}{|c|}{ Marandu } & \multirow{2}{*}{ SEM } & \multicolumn{3}{|c|}{$P$-value } \\
\hline & $0.0 \%$ & $1.5 \%$ & $3.0 \%$ & $\overline{0.0 \%}$ & $1.5 \%$ & $3.0 \%$ & & G & C & $\bar{G} \times \mathrm{C}$ \\
\hline $\mathrm{pH}$ & 5.62 & 5.57 & 5.64 & 5.81 & 5.62 & 5.64 & 0.591 & 0.10 & 0.11 & 0.37 \\
\hline Luminosity & 38.48 & 35.98 & 35.46 & 39.80 & 37.03 & 33.00 & 0.173 & 0.92 & 0.04 & 0.27 \\
\hline Intensity of red & 13.41 & 14.03 & 14.65 & 13.42 & 14.83 & 17.06 & 1.041 & 0.40 & 0.37 & 0.75 \\
\hline Intensity of yellow & 6.14 & 4.42 & 5.42 & 6.67 & 4.99 & 6.32 & 0.632 & 0.02 & $<0.01$ & 0.83 \\
\hline Saturation index & 14.79 & 14.77 & 15.77 & 15.09 & 15.66 & 18.28 & 1.367 & 0.31 & 0.38 & 0.76 \\
\hline Tone angle & 25.09 & 18.25 & 20.34 & 26.65 & 18.53 & 20.31 & 3.177 & 0.54 & 0.04 & 0.80 \\
\hline Water holding capacity & 77.20 & 79.30 & 81.06 & 81.32 & 77.36 & 79.62 & 1.677 & 0.86 & 0.72 & 0.21 \\
\hline Loss of cooking & 25.18 & 30.37 & 35.12 & 20.74 & 28.40 & 33.21 & 3.803 & 0.34 & 0.21 & 0.63 \\
\hline Shear force & $2.30^{b}$ & $3.39^{\mathrm{a}}$ & $2.78^{\mathrm{ab}}$ & $2.76^{\mathrm{ab}}$ & $2.17^{\mathrm{b}}$ & $2.45^{b}$ & 0.240 & 0.09 & 0.02 & 0.01 \\
\hline
\end{tabular}

\footnotetext{
${ }^{a, b}$ Means in the same row with different superscripts are different $(P<0.05)$ for interaction between grass and concentrate level
}

For FA content, there was an interaction between concentrate levels and grass (Table 3). Meat from animals on Aruana grass pasture and supplemented at $1.5 \%$ of their BW had greater FA content, while animals on Marandu grass pasture had higher FA content when they received concentrate at $3.0 \%$ of their BW. The total quantity of saturated fatty acids (SFAs) was not affected by the treatments, but differences between treatments were found for some individual SFAs. Meat from animals on Aruana grass pasture and supplemented at $3.0 \%$ of their BW had the greatest capric fatty acid (C10:0) meat, while animals on Marandu grass pasture without supplementation had more C10:0. Tridecylic (C13:0) and pentadecylic (C15:0) acids were reduced when lambs were supplemented at $1.5 \%$ or $3.0 \%$ of their BW. The stearic acid content increased when the animals were supplemented at 1.5\% of their BW. Margaric (C17:0) and arachidic (C20:0) acid contents were greater in the meat from lambs on Marandu grass without supplementation, followed by the lambs on Aruana grass without supplementation, and lowest in the meat from animals on Aruana grass with $3.0 \%$ concentrate supplement.

The total dimethyl acetals (DMAs) decreased with 1.5\% concentrate supplementation due to a reduction in palmitic acid DMA. The total BCFAs were consistently greater for animals that grazed Marandu grass. The total and individual BCFAs were also greater for animals that were not supplemented and similarly for the individual BCFAs $i-\mathrm{C} 13: 0, a-C 13: 0, i-\mathrm{C} 14: 0, a-\mathrm{C} 15: 0, i-\mathrm{C} 16: 0, i-\mathrm{C} 17: 0, a-\mathrm{C} 17: 0$ and $i-\mathrm{C} 18: 0$. Only a-C18:0 responded differently, being reduced when the lambs were supplemented at $1.5 \%$ of their BW. 
Table 3 Saturated fatty acid content ( $\mathrm{g} / \mathrm{kg}$ of total lipid) of Longissimus thoracis et lumborum muscle of lambs that grazed Aruana or Marandu grass and were supplemented with concentrate at $0.0 \%, 1.5 \%$ or $3.0 \%$ of bodyweight

\begin{tabular}{|c|c|c|c|c|c|c|c|c|c|c|}
\hline \multirow{2}{*}{$\begin{array}{l}\text { Grass } \\
\text { Supplement }\end{array}$} & \multicolumn{3}{|c|}{ Aruana } & \multicolumn{3}{|c|}{ Marandu } & \multirow{2}{*}{ SEM } & \multicolumn{3}{|c|}{$P$-value } \\
\hline & $0.0 \%$ & $1.5 \%$ & $3.0 \%$ & $0.0 \%$ & $1.5 \%$ & $3.0 \%$ & & $\mathrm{G}$ & C & $G \times C$ \\
\hline \multicolumn{11}{|l|}{ Fatty acid $^{1}$} \\
\hline Total, g/kg meat & $766.35^{c}$ & $830.77^{\mathrm{a}}$ & $812.19^{\mathrm{ar}}$ & $786.75^{\mathrm{ab}}$ & $771.84^{\mathrm{bc}}$ & $827.93^{\mathrm{a}}$ & 23.182 & 0.72 & 0.32 & 0.04 \\
\hline SFA & 374.86 & 415.98 & 365.76 & 407.59 & 392.71 & 391.47 & 11.833 & 0.31 & 0.19 & 0.14 \\
\hline $\mathrm{C} 10: 0$ & $1.78^{\mathrm{ab}}$ & $1.73^{\mathrm{b}}$ & $2.45^{\mathrm{a}}$ & $2.48^{\mathrm{a}}$ & $1.95^{\mathrm{ab}}$ & $1.70^{\mathrm{b}}$ & 0.242 & 0.80 & 0.52 & 0.04 \\
\hline C12:0 & 4.59 & 2.77 & 3.68 & 5.97 & 2.32 & 2.76 & 0.930 & 0.99 & 0.11 & 0.56 \\
\hline C13:0 & 0.23 & 0.15 & 0.12 & 0.28 & 0.14 & 0.14 & 0.024 & 0.44 & 0.01 & 0.47 \\
\hline C14:0 & 32.39 & 21.44 & 19.19 & 36.19 & 17.80 & 24.38 & 4.125 & 0.64 & 0.04 & 0.56 \\
\hline C15:0 & 5.41 & 3.45 & 2.98 & 6.43 & 3.20 & 3.43 & 0.288 & 0.31 & $<0.01$ & 0.44 \\
\hline C16:0 & 153.45 & 164.26 & 154.16 & 160.52 & 152.53 & 166.13 & 7.733 & 0.74 & 0.93 & 0.36 \\
\hline C17:0 & $8.59^{\mathrm{b}}$ & $7.03^{\mathrm{cd}}$ & $6.97^{\mathrm{d}}$ & $9.81^{\mathrm{a}}$ & $6.64^{\mathrm{d}}$ & $7.43^{c}$ & 0.119 & 0.01 & $<0.01$ & 0.01 \\
\hline C18:0 & 165.57 & 212.68 & 173.95 & 182.79 & 205.93 & 183.17 & 3.716 & 0.10 & $<0.01$ & 0.07 \\
\hline $\mathrm{C} 20: 0$ & $1.86^{\mathrm{b}}$ & $1.75^{\mathrm{b}}$ & $1.44^{\mathrm{c}}$ & $2.14^{\mathrm{a}}$ & $1.55^{\mathrm{c}}$ & $1.53^{\mathrm{c}}$ & 0.047 & 0.23 & $<0.01$ & 0.01 \\
\hline $\mathrm{C} 22: 0$ & 0.43 & 0.37 & 0.46 & 0.49 & 0.36 & 0.41 & 0.026 & 0.95 & 0.04 & 0.24 \\
\hline C23:0 & 0.56 & 0.34 & 0.36 & 0.49 & 0.30 & 0.40 & 0.104 & 0.79 & 0.29 & 0.88 \\
\hline DMA & 17.16 & 11.80 & 18.03 & 18.42 & 12.83 & 14.93 & 1.617 & 0.86 & 0.04 & 0.41 \\
\hline C16:0 DMA & 9.74 & 5.99 & 9.97 & 11.73 & 6.21 & 8.48 & 1.067 & 0.77 & 0.01 & 0.31 \\
\hline C17:0 DMA & 7.42 & 5.81 & 8.05 & 6.69 & 6.62 & 6.45 & 0.760 & 0.48 & 0.42 & 0.35 \\
\hline BCFA & 16.34 & 13.16 & 11.90 & 18.99 & 13.45 & 12.08 & 0.846 & 0.22 & $<0.01$ & 0.42 \\
\hline$i-\mathrm{C} 13: 0$ & $0.07^{\mathrm{b}}$ & $0.04^{c}$ & $0.03^{c}$ & $0.12^{\mathrm{a}}$ & $0.04^{c}$ & $0.03^{c}$ & 0.005 & 0.02 & $<0.01$ & 0.04 \\
\hline$a-C 13: 0$ & 0.07 & 0.04 & 0.03 & 0.10 & 0.05 & 0.04 & 0.007 & 0.02 & $<0.01$ & 0.12 \\
\hline$i-\mathrm{C} 14: 0$ & 1.00 & 0.55 & 0.42 & 1.23 & 0.57 & 0.52 & 0.080 & 0.16 & $<0.01$ & 0.55 \\
\hline$a-c 15: 0$ & 3.11 & 2.03 & 1.58 & 3.98 & 2.01 & 1.78 & 0.224 & 0.13 & $<0.01$ & 0.28 \\
\hline$i-\mathrm{C} 16: 0$ & 1.84 & 1.31 & 1.04 & 2.15 & 1.47 & 1.27 & 0.105 & 0.16 & 0.02 & 0.91 \\
\hline$i-\mathrm{C} 17: 0$ & 3.60 & 3.55 & 3.10 & 4.06 & 3.35 & 3.01 & 0.202 & 0.56 & 0.04 & 0.47 \\
\hline$a-C 17: 0$ & 4.08 & 3.76 & 3.14 & 4.81 & 3.86 & 3.27 & 0.154 & 0.07 & $<0.01$ & 0.22 \\
\hline$i-\mathrm{C} 18: 0$ & 1.06 & 0.80 & 0.61 & 1.15 & 0.87 & 0.73 & 0.035 & 0.04 & $<0.01$ & 0.77 \\
\hline$a-C 18: 0$ & 1.51 & 1.07 & 1.94 & 1.38 & 1.09 & 1.42 & 0.167 & 0.22 & 0.04 & 0.34 \\
\hline
\end{tabular}

${ }^{1}$ SFA: saturated fatty acids (sum of 10:0, 12:0, 13:0, 14:0, 15:0, 16:0, 17:0, 18:0, 20:0, 22:0, and 23:0); C10:0: capric; C12:0: lauric; C13:0: tridecanoic C14:0: myristic; C15:0: pentadecanic; C16:0: palmitic; C17:0: heptadecanoic; C18:0: stearic; C20:0: arachidic; C22:0: behenic; DMA: dimethyl acetals (sum of C16:0 DMA and C17:0 DMA); BCFA: branched chain fatty acids (sum of $i-13: 0, a-13: 0, i-14: 0, a-15: 0, i-16: 0, i-17: 0, a-17: 0, i-18: 0$, and a-18:0 (a: anteiso, $i$ : iso)).

$a, b, c$ Means in the same row with different superscripts are different $(P<0.05)$ for interaction between grass and concentrate level.

Total monounsaturated fatty acids (MUFAs) increased with concentrate supplementation (Table 4), although C14:1t9, C16:1t9, C16:1c7 and C17:1c9 were reduced with supplementation. The increase in MUFAs was because of increased long-chain MUFA content (C18:1t5, C18:1c9, C18:1t10, C18:1c12, C18:1c13, C18:1t15 and C18:1t16) with concentrate supplementation. For C18:1t11 and C18:1c11, the low content was in meat from animals that were supplemented with concentrate at $1.5 \%$ of BW. The MUFAs C16:1t9, and C18:1c12 were greater in meat from animals on Aruana grass pasture, and only C14:1t9 was elevated in meat from animals on Marandu grass pasture. 
Table 4 Unsaturated fatty acid content ( $\mathrm{g} / \mathrm{kg}$ of total lipid) of Longissimus thoracis et lumborum muscle of lambs that grazed Aruana or Marandu grass and were supplemented with concentrate at $0.0 \%, 1.5 \%$ or $3.0 \%$ of body weight

\begin{tabular}{|c|c|c|c|c|c|c|c|c|c|c|}
\hline \multirow{2}{*}{$\begin{array}{l}\text { Grass } \\
\text { Supplementation }\end{array}$} & \multicolumn{3}{|c|}{ Aruana } & \multicolumn{3}{|c|}{ Marandu } & \multirow[t]{2}{*}{ SEM } & \multicolumn{3}{|c|}{$P$-value } \\
\hline & $0.0 \%$ & $1.5 \%$ & $3.0 \%$ & $0.0 \%$ & $1.5 \%$ & $3.0 \%$ & & G & C & $G \times C$ \\
\hline MUFA & 286.78 & 323.69 & 310.28 & 273.85 & 288.90 & 320.44 & 13.039 & 0.32 & 0.04 & 0.13 \\
\hline C14:1t9 & 2.03 & 1.37 & 0.89 & 2.52 & 1.41 & 1.10 & 0.118 & 0.06 & $<0.01$ & 0.31 \\
\hline C14:1c9 & 0.66 & 0.44 & 0.46 & 0.75 & 0.33 & 0.57 & 0.084 & 0.75 & 0.12 & 0.60 \\
\hline C16:1t9 & 1.09 & 0.45 & 0.60 & 0.87 & 0.32 & 0.58 & 0.064 & 0.07 & $<0.01$ & 0.41 \\
\hline C16:1c7 & 3.90 & 3.03 & 2.87 & 4.34 & 3.11 & 3.15 & 0.272 & 0.31 & 0.02 & 0.84 \\
\hline C16:1c9 & 6.81 & 6.42 & 5.63 & 6.51 & 5.72 & 6.85 & 0.769 & 0.91 & 0.79 & 0.48 \\
\hline C17:1c9 & 2.91 & 2.22 & 2.33 & 2.91 & 2.03 & 2.47 & 0.108 & 0.87 & $<0.01$ & 0.38 \\
\hline C18:1t5 & 0.10 & 0.19 & 0.29 & 0.12 & 0.16 & 0.25 & 0.031 & 0.55 & 0.01 & 0.63 \\
\hline C18:1t9 & 2.09 & 2.29 & 2.59 & 1.98 & 1.90 & 2.64 & 0.280 & 0.57 & 0.19 & 0.74 \\
\hline C18:1c9 & 220.23 & 258.41 & 232.39 & 212.41 & 239.45 & 248.45 & 7.058 & 0.59 & 0.02 & 0.13 \\
\hline C18:1t10 & 2.68 & 5.31 & 14.26 & 2.61 & 3.45 & 10.46 & 2.507 & 0.21 & $<0.01$ & 0.57 \\
\hline C18:1t11 & 24.19 & 15.95 & 18.63 & 19.74 & 10.69 & 16.95 & 2.177 & 0.11 & 0.04 & 0.71 \\
\hline C18:1c11 & 6.78 & 6.59 & 8.32 & 6.30 & 6.09 & 8.05 & 0.374 & 0.26 & $<0.01$ & 0.95 \\
\hline C18:1t12 & 2.15 & 6.18 & 4.40 & 2.01 & 2.31 & 3.19 & 1.664 & 0.28 & 0.53 & 0.59 \\
\hline C18:1c12 & 0.65 & 1.89 & 2.66 & 0.49 & 1.13 & 2.03 & 0.271 & 0.08 & $<0.01$ & 0.62 \\
\hline C18:1c13 & 0.21 & 0.39 & 0.55 & 0.16 & 0.29 & 0.47 & 0.080 & 0.34 & 0.04 & 0.96 \\
\hline C18:1c14 & 0.37 & 0.29 & 0.30 & 0.29 & 0.26 & 0.37 & 0.058 & 0.75 & 0.59 & 0.50 \\
\hline C18:1t15 & 2.31 & 2.89 & 2.89 & 2.01 & 2.70 & 2.86 & 0.149 & 0.24 & 0.02 & 0.72 \\
\hline C18:1c15 & 0.39 & 0.35 & 0.51 & 0.41 & 0.36 & 0.42 & 0.057 & 0.71 & 0.27 & 0.61 \\
\hline C18:1t16 & 2.07 & 2.74 & 2.62 & 2.00 & 2.08 & 2.68 & 0.110 & 0.07 & 0.01 & 0.05 \\
\hline C18:1c16 & 0.45 & 0.51 & 0.64 & 0.47 & 0.41 & 0.60 & 0.058 & 0.45 & 0.08 & 0.67 \\
\hline C20:1c11 & 0.82 & 0.75 & 0.82 & 0.80 & 0.62 & 0.81 & 0.090 & 0.55 & 0.36 & 0.77 \\
\hline PUFA & 71.34 & 66.38 & 106.45 & 68.13 & 64.10 & 89.25 & 4.686 & 0.13 & $<0.01$ & 0.31 \\
\hline $\mathrm{C} 18-2 \mathrm{cc}$ & 24.52 & 32.59 & 60.92 & 22.20 & 33.20 & 49.76 & 2.728 & 0.13 & $<0.01$ & 0.18 \\
\hline C18:3n-6 & 0.17 & 0.31 & 0.37 & 0.18 & 0.34 & 0.34 & 0.039 & 0.85 & 0.02 & 0.73 \\
\hline C18:3n-3 & 0.74 & 0.44 & 0.51 & 0.59 & 0.32 & 0.44 & 0.485 & 0.04 & $<0.01$ & 0.72 \\
\hline C18:4n-3 & 0.25 & 0.17 & 0.09 & 0.24 & 0.15 & 0.14 & 0.009 & 0.30 & $<0.01$ & 0.05 \\
\hline C20:2n-6 & 0.15 & 0.21 & 0.36 & 0.12 & 0.17 & 0.28 & 0.029 & 0.14 & $<0.01$ & 0.73 \\
\hline C20:3n-6 & 0.89 & 0.87 & 0.15 & 0.11 & 0.89 & 0.13 & 0.117 & 0.99 & 0.01 & 0.20 \\
\hline$C 20: 4 n-6$ & 11.59 & 9.41 & 16.90 & 14.70 & 10.68 & 13.17 & 1.125 & 0.83 & 0.02 & 0.08 \\
\hline C20:5n-3 & 3.00 & 1.26 & 1.61 & 3.11 & 1.14 & 1.28 & 0.282 & 0.58 & $<0.01$ & 0.79 \\
\hline$C 22: 4 n-6$ & 0.77 & 0.75 & 1.13 & 0.99 & 0.89 & 0.95 & 0.096 & 0.50 & 0.15 & 0.21 \\
\hline$C 22: 5 n-6$ & 0.16 & 0.20 & 0.30 & 0.15 & 0.27 & 0.31 & 0.053 & 0.62 & 0.13 & 0.77 \\
\hline$C 22: 5 n-3$ & 5.59 & 2.80 & 3.91 & 6.19 & 2.60 & 3.26 & 0.449 & 0.84 & $<0.01$ & 0.50 \\
\hline$C 22: 6 n-3$ & 0.95 & 0.66 & 0.86 & 0.75 & 0.51 & 0.70 & 0.104 & 0.12 & 0.14 & 0.97 \\
\hline CLA (c9-t11) & 6.69 & 5.42 & 5.88 & 4.51 & 3.95 & 5.92 & 0.811 & 0.15 & 0.38 & 0.48 \\
\hline CALA & 4.28 & 2.84 & 2.72 & 3.41 & 2.90 & 2.65 & 0.259 & 0.24 & 0.02 & 0.33 \\
\hline Other CLA & 0.74 & 0.65 & 0.49 & 0.49 & 0.40 & 0.68 & 0.104 & 0.29 & 0.71 & 0.16 \\
\hline Other nc C18:2 & 4.04 & 3.57 & 4.03 & 3.85 & 2.72 & 3.85 & 0.293 & 0.17 & 0.07 & 0.49 \\
\hline$n-6$ & 38.25 & 44.34 & 81.56 & 39.50 & 46.46 & 66.12 & 3.708 & 0.27 & $<0.01$ & 0.12 \\
\hline$n-3$ & 17.20 & 9.30 & 11.56 & 16.15 & 7.52 & 9.80 & 1.237 & 0.21 & $<0.01$ & 0.95 \\
\hline$n-6 / n-3$ & 2.26 & 4.81 & 7.09 & 2.43 & 6.19 & 6.95 & 2.779 & 0.11 & $<0.01$ & 0.09 \\
\hline
\end{tabular}

MUFA: monounsaturated fatty acids (sum of 14:1c9, 14:1t9, 16:1t9, 16:1c7, 16:1c9, 17:1c9, 18:1t5, 18:1t9, 18:1c9, 18:1t10, 18:1t11, 18:1c11, 18:1t12, 18:1c12, 18:1c13, 18:1c14, 18:1t15, 18:1c15, 18:1t16, 18:1c16 and 20:1c11); C14:1: myristoleic; C16:1: palmitoleic acid; C17:1: heptadecenoic; C18:1: vaccenic acid; C20:1: paullinic; PUFA: polyunsaturated fatty acids (sum of 18:3n-6, 18:3n-3, 18:4n-3, CLA (conjugated linoleic acids), CALA (conjugated 
a-linolenic acid), 20:2n-6, 20:3n-6, 20:4n-6, 20:5n-3, 22:4n-6, 22:5n-6, 22:5n-3, and 22:6n-3); C18:2: linoleic acid; C18:3: $\alpha$ - and $\gamma$-Linolenic acid; C18:4: $\alpha$-Parinaric; C20:2: eicosadienoic; C20:3: dihomo- $\gamma$-linolenic; C20:4: arachidonic; C20:5: eicosapentaenoic; C22:4: docosatetraenoic; C22:5: docosapentaenoic; C22:6: docosahexaenoic; $n-3$ : sum of 18:3n-3, 18:4n-3 20:5n-3, 22:5n-3 and 22:6n-3; n-6: sum of 18:3n-6, 20:2n-6, 20:3n-6, 20:4n-6, 22:4n-6, and 22:5n-6) Means in the same row with different superscripts are different $(P<0.05)$ for interaction between grass and concentrate level

Supplementation at 3.0\% increased total polyunsaturated fatty acids (PUFAs), following the individual levels of C18:3n-6, C20:2n-6 and C20:4n-6, but not C18:3n-3, C18:4n-3, C20:3n-6, C20:5n-3 and C22:5n-3. The latter group of PUFAs were reduced with concentrate supplementation and the level of C22:4n-6 did not change. The level of conjugated $\alpha$-Linolenic acid (CALA) was greater in the meat of animals that were supplemented with concentrate. The sum of n-6 PUFAs increased and sum of n-3 PUFAs decreased with the feeding of supplement resulting in an increase in the $n-6 / n-3$ ratio with supplementation.

The PCA analysis is used to define principal components (PCs). The PCs are formed with linear combinations of the original variables. The first PC is the linear function that explains the greatest proportion of variation of the original data. The combination between the first and second PCs generates four quadrants based on the correlation of variables. (Quadrant 1 is positive for PC1 and negative for PC2; Quadrant 2 is positive for both PCs, Quadrant 3 is negative for both PCs, and Quadrant 4 is negative for PC1 and positive for PC2.) The graphic representation expresses the rotation between the original variables with PC1 and $\mathrm{PC} 2$, resulting in grouping the ellipsoids of the most correlated variables.

The PCA of the FA groups resulted in a division of cases according to the concentration levels in the diet (Figure 1), in which $33.33 \%$ of animals that received $3.0 \%$ supplementation were allocated to the third quadrant, and $88.89 \%$ of animals that did not receive supplementation were allocated to the fourth quadrant.
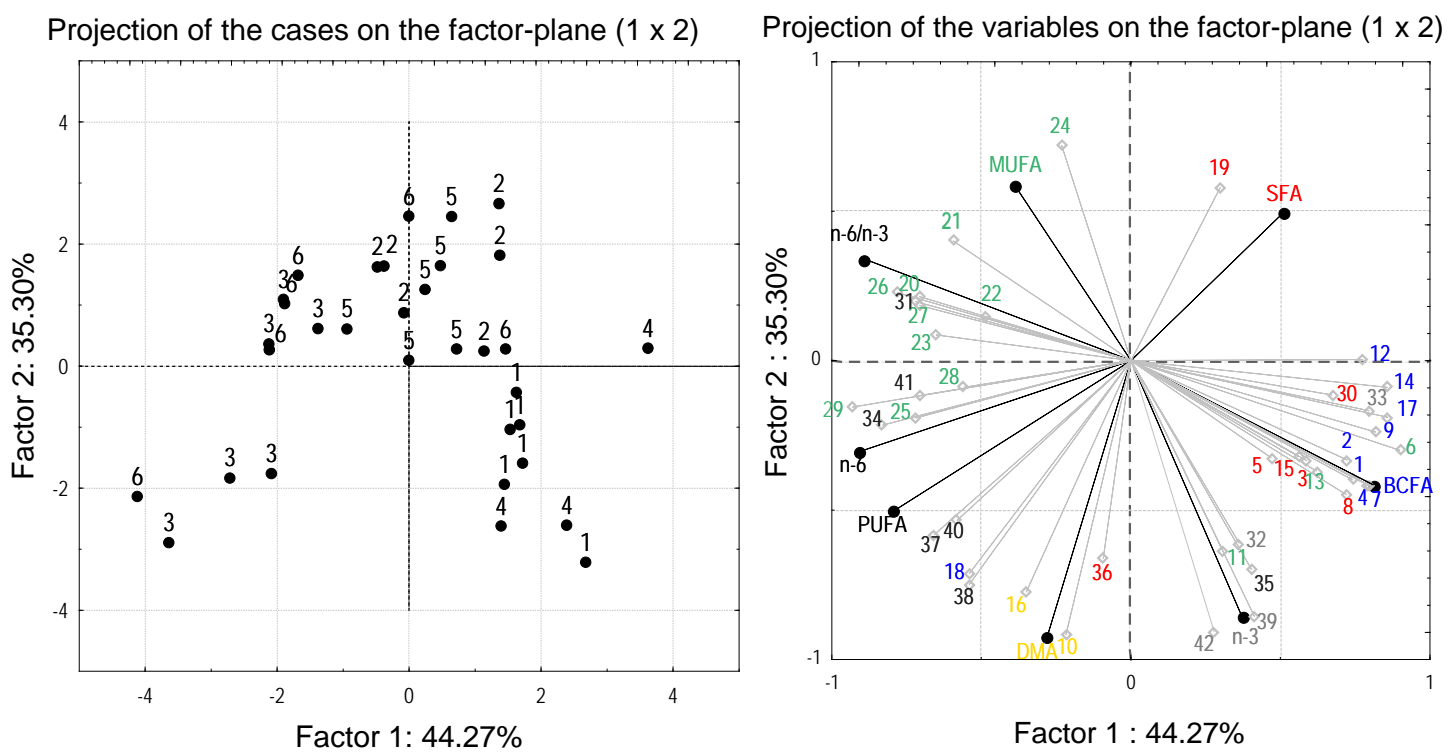

Figure 1 Principal component analysis of fatty acid groups relation to fatty acids of Longissimus thoracis et lumborum muscle of meat from lambs that grazed Aruana or Marandu grass and were supplemented with concentrate at $0.0 \%, 1.5 \%$ or $3.0 \%$ of bodyweight

Cases plot: 1: Aruana $+0.0 \%$ of supplementation; 2 : Aruana $+1.5 \%$ of supplementation; 3 : Aruana $+3.0 \%$ of supplementation; 4 : Marandu $+0.0 \%$ of supplementation; 5 : Marandu $+1.5 \%$ of supplementation; 6 : Marandu $+3.0 \%$ of supplementation. Variables plot, active variables in bold: SFA: saturated fatty acids; MUFA: monounsaturated fatty acids; PUFA: polyunsaturated fatty acids; PUFA n-3; PUFA n-6; relation between PUFA n-3 and n-6; BCFA: branched chain fatty acids; DMA: total of dimethyl acetals; supplementary variables in gray: 1 : i-C13:0; 2 : a-C13:0; 3: C13:0 tridecanoic; 4: i-C14:0; 5: C14:0 myristic; 6: C14:1c9 myristoleic; 7: a-C15:0; 8: C15:0 pentadecanic; 9: i-C16:0; 10: C16:0 palmitic DMA; 11: C16:1t9 palmitoleic; 12: i-C17:0; 13: C16:1c7; 14: a-17:0; 15: C17:0 heptadecanoic; 16: C17 DMA; 17: i-C18:0; 18: a-C18:0; 19: C18:0 stearic; 20: C18:1t5 vaccenic; 21: C18:1t6-8; 22: C18:1t9; 23: C18:1t10; 24: C18:1c9; 25: C18:1c11; 26: C18:1c12; 27: C18:1c13; 28: C18:1c16; 29: C18:2cc linoleic; 30: C20:0 arachidic; 31: C18:3n6 a- and YLinolenic; 32: C18:3n3; 33: C18:4n3 a-Parinaric; 34: C20:2n6 eicosadienoic; 35: conjugated a-linolenic acid; 36: C22:0 behenic; 37: C20:3n6 dihomo-y-linolenic; 38: C20:4n6 arachidonic; 39: C20:5n3 eicosapentaenoic; 40: C22:4n6 docosatetraenoic; 41: C22:5n6 docosapentaenoic; 42: C22:5n3 
The first quadrant (positive values for PC1 and PC2) was based on the correlations of MUFA and the $n-6 / n-3$ ratio. The second quadrant was based on the SFA correlation. The third quadrant was based on the correlations of PUFA, $n-6$, and DMA. The fourth quadrant was based on the correlations of BCFA and $n-3$. The supplementary variables used in the PCA analysis were the individual FAs, which showed that the total SFAs had a large positive correlation with the amount of C18:0, just as the total MUFAs had a high correlation with C18:1c9 and C18:1t6. The total BCFAs had a high correlation with the amount of $i-13: 0$, a13:0, $i-14: 0, a-15: 0$ and other FAs that are not BCFAs. The total PUFAs had a high correlation with $\mathrm{n}-6 \mathrm{FAs}$, but showed a large negative correlation with n-3 FAs. The n-3 FAs were negatively correlated with the n-6/n3 ratio.

For sensory characteristics (Table 5), lambs feed with Aruana grass received more points on the ergonomic scale for meat appearance than Marandu grass, regardless of the level of supplementation. Meat from animals that received supplementation with $3.0 \%$ concentrate was rated lower on meat flavour and global appreciation.

Table 5 Sensory analysis of the Longissimus thoracis et lumborum muscle, of meat from lambs that grazed Aruana or Marandu grass and were supplemented with concentrate at $0.0 \%, 1.5 \%$ or $3.0 \%$ of bodyweight

\begin{tabular}{|c|c|c|c|c|c|c|c|c|c|c|}
\hline \multirow{2}{*}{$\begin{array}{l}\text { Grass } \\
\text { supplementation }\end{array}$} & \multicolumn{3}{|c|}{ Aruana } & \multicolumn{3}{|c|}{ Marandu } & \multirow[b]{2}{*}{ SEM } & \multicolumn{3}{|c|}{$P$-value } \\
\hline & $0.0 \%$ & $1.5 \%$ & $3.0 \%$ & $0.0 \%$ & $1.5 \%$ & $3.0 \%$ & & $G$ & C & $\mathrm{G} \times \mathrm{C}$ \\
\hline Appearance & $8.25^{\mathrm{A}}$ & $8.05^{\mathrm{A}}$ & $8.05^{\mathrm{A}}$ & $7.73^{\mathrm{B}}$ & $7.77^{\mathrm{B}}$ & $7.70^{\mathrm{B}}$ & 0.189 & 0.02 & 0.87 & 0.92 \\
\hline Flavour & $7.90^{\mathrm{a}}$ & $7.70^{\mathrm{a}}$ & $7.19^{\mathrm{b}}$ & $7.97^{\mathrm{a}}$ & $7.98^{\mathrm{a}}$ & $7.51^{\mathrm{b}}$ & 0.213 & 0.38 & 0.01 & 0.83 \\
\hline Fat flavour & 6.80 & 6.47 & 6.33 & 7.21 & 6.75 & 6.40 & 0.262 & 0.47 & 0.08 & 0.82 \\
\hline Odour & 7.45 & 7.59 & 7.33 & 7.67 & 7.10 & 7.03 & 0.209 & 0.28 & 0.25 & 0.29 \\
\hline Softness & 8.90 & 9.01 & 8.43 & 8.31 & 8.64 & 8.18 & 0.172 & 0.14 & 0.21 & 0.21 \\
\hline Global appreciation & $8.00^{\mathrm{a}}$ & $7.86^{\mathrm{a}}$ & $7.51^{\mathrm{b}}$ & $8.15^{\mathrm{a}}$ & $7.92^{\mathrm{a}}$ & $7.46^{\mathrm{b}}$ & 0.194 & 0.95 & 0.01 & 0.88 \\
\hline
\end{tabular}

Means in the same row with different uppercase superscripts are different $(P<0.05)$ for grass. Means in the same row with different lowercase superscripts are different $(P<0.05)$ for level of concentrate.

According to the PCA analysis of the sensory aspects, global appreciation had large positive correlations with flavour and fat flavour (Figure 2), but the authors were not able to allocate the cases of treatments into groups. The supplementary variables (instrumental indicators and FA groups) showed a low correlation with the sensory variables. The discriminant analysis of the sensory aspects corroborated the PCA, and only $18 \%$ of the samples were grouped according to the treatments (Table 6 ), but $61 \%$ of the samples from lamb fed Marandu grass without supplementation were grouped into the correct treatment. This indicates that those animals presented characteristics that were distinct from those who received the other treatments. Animals from this group also received higher scores for sensory analysis.

In terms of consumer interest and willingness to buy the meat, $92 \%$ of consumers involved in sensory testing reported that they would buy the sheep meat and $8 \%$ claimed that would not buy the meat. The average purchase value was $\$ 5.91$ per $\mathrm{kg}$. 


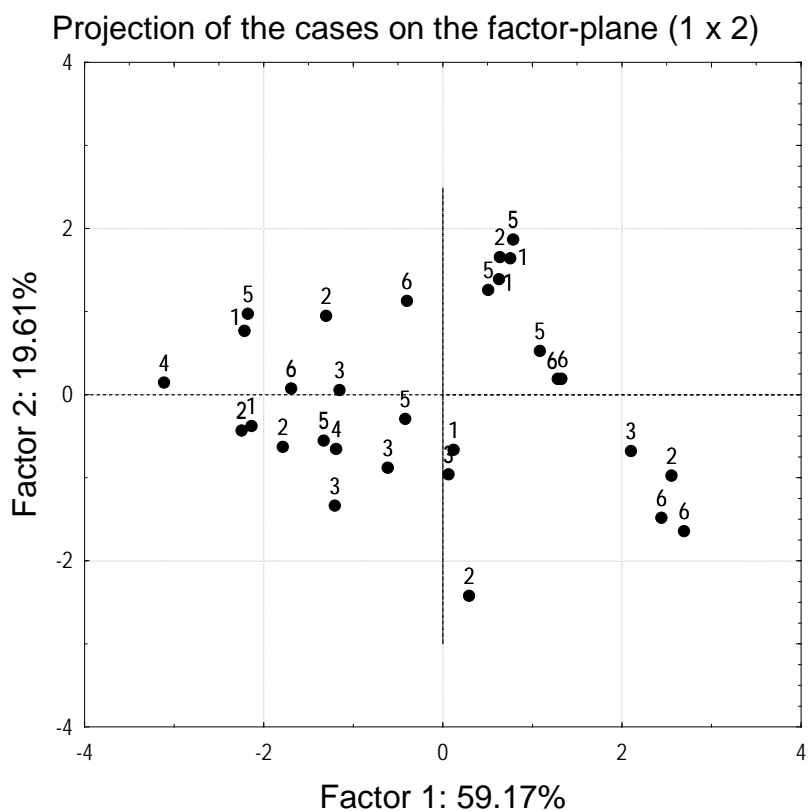

Projection of the variables on the factor-plane $(1 \times 2)$

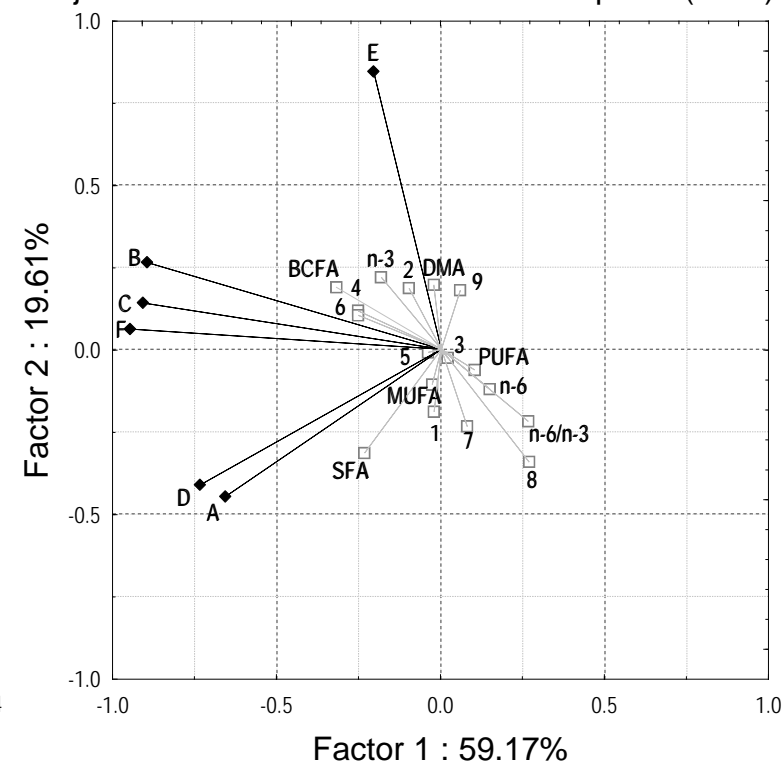

Figure 2 Principal component analysis of sensory properties and physical characteristics, and fatty acids groups of Longissimus thoracis et lumborum muscle of meat from lambs that grazed Aruana or Marandu grass and were supplemented with concentrate at $0.0 \%, 1.5 \%$, and $3.0 \%$ of bodyweight

Cases plot: 1: Aruana $+0.0 \%$ of supplementation; 2: Aruana $+1.5 \%$ of supplementation; 3 : Aruana $+3.0 \%$ of supplementation; 4 : Marandu $+0.0 \%$ of supplementation; 5 : Marandu $+1.5 \%$ of supplementation; 6 : Marandu $+3.0 \%$ of supplementation. Variables plot, active variables in bold: A: appearance; B: flavour; C: fat flavour; D: odour; E: softness; F: global appreciation; supplementary variables in gray: $1: \mathrm{pH} ; 2$ : luminosity; 3 : intensity of red; 4: intensity of yellow; 5 : saturation index; 6: tone angle; 7: water-holding capacity; 8: loss of cooking; 9: shear force; SFA: saturated fatty acids; MUFA: monounsaturated fatty acids; PUFA: polyunsaturated fatty acids; PUFA n-3; PUFA n-6; n-6/n-3- relation between PUFA n-3 and n-6; BCFA: branched chain fatty acids; DMA: total of dimethyl acetals

Table 6 Ability of consumers to assign meat samples to treatments that were applied to the lambs that produced the samples

\begin{tabular}{|c|c|c|c|c|c|c|c|}
\hline \multirow{3}{*}{\multicolumn{2}{|c|}{ Treatments as assigned by consumers }} & \multicolumn{6}{|c|}{ Treatments applied $^{1}$} \\
\hline & & \multicolumn{3}{|c|}{ Aruana } & \multicolumn{3}{|c|}{ Marandu } \\
\hline & & $0.0 \%$ & $1.5 \%$ & $3.0 \%$ & $0.0 \%$ & $1.5 \%$ & $3.0 \%$ \\
\hline \multirow{3}{*}{ Aruana } & $0.0 \%$ & 16 & 17 & 16 & 6 & 28 & 16 \\
\hline & $1.5 \%$ & 18 & 22 & 25 & 5 & 10 & 21 \\
\hline & $3.0 \%$ & 19 & 18 & 26 & 5 & 12 & 19 \\
\hline \multirow{3}{*}{ Marandu } & $0.0 \%$ & 49 & 48 & 41 & 37 & 53 & 42 \\
\hline & $1.5 \%$ & 14 & 10 & 9 & 4 & 10 & 15 \\
\hline & $3.0 \%$ & 9 & 10 & 8 & 3 & 12 & 12 \\
\hline Total number & & 125 & 125 & 125 & 60 & 125 & 125 \\
\hline Number correct & & 16 & 22 & 26 & 37 & 10 & 12 \\
\hline Proportion correct & & 0.128 & 0.176 & 0.208 & 0.617 & 0.080 & 0.096 \\
\hline
\end{tabular}

$\mathrm{N}$ total: $685 ; \mathrm{N}$ correct: 123 ; proportion correct: 0.180 . 


\section{Discussion}

The $\mathrm{pH}$ values revealed that rigor mortis had occurred normally (Araújo, 2012) and the quality of the analysed meat was adequate. When $\mathrm{pH}$ values are lower, water retention capacity is lost and the taste, colour and texture of the meat are impaired (Ramos et al., 2009). Animals that received concentrate supplementation were less luminous and had greater FA content. This is opposite of the observations of Ferrer-González et al. (2019), who found luminosity was directly proportional to fat content because meat that contains more fat is lighter in colour. The values for weight loss by cooking were not expected, because greater amounts of fat are typically associated with there being less water in the meat and consequently less loss due to evaporation or dripping (Carrasco et al., 2009). However, none of the meat was evaluated as dry or hard, which would be related to the release of exudate, with this compromising the nutritional value of the meat (Zeola et al., 2007). According to the SF, the animals fed with Aruana grass only and the animals fed with Marandu grass plus concentrate supplementation showed greater meat softness. However, this could not be detected by the sensory core panellists. The SF represents the toughness of meat and is included as a consumer-relevant trait (Hopkins et al., 2010). Some of the alterations in FAs that were observed may be related to the amount of these FAs in the feed of the animals. For example, tridecylic, pentadecylic and margaric acids were low in animals with supplementation, probably because there are more long-chain fatty acids in the concentrate, and also because the body can synthesise these FAs (Scollan et al., 2006). Also, the reduction in palmitic acid in the meat of supplemented animals was because of the lower amount of this acid in the concentrate supplement (Table 1).

The DMAs are formed from cleavage of the vinyl ether chain, which is located at the sn-1 position of their glycerol backbone and can be used to evaluate the plasmalogen phospholipids (Fonteles et al., 2018). The content of plasmalogens can be associated with the abundance of long-chain PUFAs in meat (Bessa et al., 2015). MUFAs and PUFAs are considered hypocholesterolaemic because they are effective in decreasing the concentration of blood cholesterol (Valsta et al., 2005). Therefore, the use of concentrate supplements with both grasses possibly indicates better nutritional quality because they contain larger quantities of MUFAs and PUFAs. On the other hand, the animals fed only on Aruana grass pasture had higher proportions of conjugated linoleic acids (CLA), and this has been observed by other authors when comparing meat lipid fractions from pasture- or concentrate-fed ruminants (Rosa et al., 2014). The $n-6 / n-3$ ratio has also been used as a criterion for the quality of fat, and should be less than 4 (Department of Health, 1994), indicating better quality of FAs in finished animals without supplementation. Pasture-finished ruminants typically have an $n-6 / n-3$ ratio of $\leq 2$ (Enser et al., 1998) and a greater PUFA/SFA ratio (French et al., 2003). The PUFA/SFA ratio ranged from 0.16 to 0.29 , being higher in animals on Aruana grass pasture plus concentrate supplementation. In meats, the PUFA/SFA ratio that has been reported to be beneficial in human diets is around 0.4 (Wood et al., 2003).

The tastiest and most appreciated meats were related to meat from lambs without concentrate supplementation or with $1.5 \%$, similar to that reported by Xue et al. (2010). Although it is possible to group the various treatments according to the FA profile, the same could not be accomplished by the sensory analysis, in which the consumers were not able to distinguish differences between treatments. This indicates that the improvement in the FA profile of the meat is not detectable by consumers. All the treatments were related to the meat that received good consumer acceptance. In general, it is possible to infer that only a limited percentage of people would be able to perceive differences in meat related to the level of supplementation, but it would be possible to differentiate animals fed with Aruana grass. A previously trained group of consumers would probably be necessary to identify differences between the meats from different treatments (Priolo et al., 2002).

Treatments that imply different rates of weight gain in lambs may not interfere with the final meat quality (Priolo et al., 2002). However, the decision to slaughter lambs in similar physiological stages (standard body condition score), rather than at a constant age, may have resulted in greater physical uniformity between samples (Osório et al., 2012). The authors emphasise that slaughter was based on the physiological stage and not after a defined period of supplementation, as may be the more usual practice in research.

\section{Conclusion}

Lambs finished on grass without supplementation had a more healthful fatty acid profile, and received better scores for flavour and global appreciation from sensory panellists. However, the differences between treatments were not detected by consumers. To improve the quality of fatty acid in the meat, the pasture system is recommended. 


\section{Acknowledgments}

Appreciation is extended to the Brazilian Federal Agency for Post-Graduate Education (CAPES; Brasilia, DF, Brazil), to the Foundation for Support to the Development of Education, Science and Technology of the State of Mato Grosso do Sul (FUNDECT; Campo Grande, MS, Brazil) and the National Research Council (CNPq; Brasilia, DF, Brazil) for the grants to the authors.

\section{Authors' contributions}

FMVJ, MR and MM designed the study; JAR, MR, GDVB, MCS, ARMF and MM collected the data; FMVJ and TF analysed the data and interpreted the results; JAR wrote the initial manuscript with revisions by FMVJ, TF and MM. All authors read and approved the manuscript prior to its submission.

\section{Conflict of Interest Declaration}

The authors declare that they have no competing interests.

\section{References}

Abdelrahman, M.M., Alhidar, I.A., Suliman, G.M., Alyemni, A.H., Al-Saiady, M.Y., ..., Aljumaah, R.S., 2018. Impact of feeding different levels of neutral detergent fiber as total mixed rations on sensory attributes, carcass characteristics and meat quality of growing lambs. Pakistan J. Zool., 50: $2129-2134$. http://dx.doi.org/10.17582/journal.pjz/2018.50.6.2129.2134

Alves, L.G.C., Fernandes, A.R.M., Osório, J.C.S., Osório, M.T.M., Nubiato, K.E.Z., ..., Catalano Neto, A.P., 2012. Detailed fatty acid composition in lamb meat in feedlot. Pubvet. 6, 1455. DOI: 10.1371/journal.pone.0058386

Araújo, C.G.F., 2012. Carcass characteristics and meat quality of sheep finished in cultivated pastures. Thesis (Master's degree in Animal Science), Federal University of Rio Grande do Norte. 60 pp.

Bessa, R.J.B., Alves, S.P. \& Santos-Silva, J. 2015. Constraints and potentials for the nutritional modulation of the fatty acid composition of ruminant meat. European Journal of Lipid Science and Technology 117:1325-1344.

Bligh, E.G. \& Dyer, W.J., 1959. A rapid method of total lipid extraction and purification. Can. J. Biochem. Phys. 37, 911917.

Boughalmi, A. \& Araba, A., 2016. Effect of feeding management from grass to concentrate feed on growth, carcass characteristics, meat quality and fatty acid profile of Timahdite lamb breed. Small Ruminant Res. 144,158-163. DOI: http://dx.doi.org/10.1016/j.smallrumres.2016.09.013

Brasil, 2000. Ministério da Agricultura Pecuária e do Abastecimento (MAPA). Secretaria da Defesa Agropecuária (SDA) Departamento de Inspeção de Produtos de Origem Animal (DIPOA). Divisão de Normas Técnicas. Instrução Normativa n. 3 de 17 de janeiro de 2000. Aprova o Regulamento Técnico de Métodos de Insensibilização para o Abate Humanitário de Animais de Açougue. Lex: Diário Oficial da União de 24 de janeiro de 2000, seção I, pág. 14-16. Brasília, 2000.

Cañeque, V. \& Sañudo, C., 2000. Metodología para el estudio de la calidad de la canal y de la carne en rumiantes. Instituto Nacional de Investigación Agropecuaria - Uruguay, 255 pp.

Carrasco, S., Panea, B., Ripoll, G. \& Joy, M., 2009. Influence of feeding systems on cortisol levels, fat colour and instrumental meat quality in light lambs. Meat Sci., 83: 50-56. DOI: 10.1016/j.meatsci.2009.03.014

$\mathrm{CIE}$, 1978. CIE recommendations on uniform color spaces-color difference equations psychometric color terms. Paris Comm. Int L'Elcairage Suppl No 2 to CIE Publication No 15 1971)(TC|13). DOI: https://doi.org/10.1002/j.15206378.1977.tb00102.x

Claffey, N.A., Fahey, A.G., Gkarane, V., Moloney, A.P., Monahan, F.J. \& Diskin, M.G., 2018. Effect of forage to concentrate ratio and duration of feeding on growth and feed conversion efficiency of male lambs. Transl. Anim. Sci., 2: 419-427. DOI: 10.1093/tas/txy071

Department of Health, 1994. Nutritional aspects of cardiovascular disease. HMSO, London. 178 pp.

Daszkiewicz, T., Purwin, C., Kubiak, D., Fijałkowska, M., Kozłowska, E. \& Antoszkiewicz, Z., 2018. Changes in the quality of meat (Longissimus thoracis et lumborum) from Kamieniec lambs during long-term freezer storage. Anim. Sci. J. 1-8. DOI: 10.1111/asj.13037

Emerenciano Neto, J.V., Pereira, G.F., Medeiros, H.R., Gracindo, A.P.A.C. \& Difante, G.S., 2011. Characterization and economic evaluation of family farming production systems in the semiarid region. Rev. Bras. Agropecu. Sustent. $1,21-28$.

Enser, M., Hallett, K.G., Hewett, B., Fursey, G.A.J., Wood, J.D. \& Harrinton, G., 1998. Fatty acid content and composition of UK beef and lamb muscle in relation to production system and implications for human nutrition. Meat Sci., 49: 329-341. DOI:10.1016/s0309-1740(97)00144-7

Faccin, T.C., Riet-Correa, F., Rodrigues, F.S., Santos, A.C., Melo, G.A., ..., Lemos, R.A.A., 2014. Poisoning by Brachiaria brizantha in flocks of naïve and experienced sheep. Toxicon, 82, 1-8. DOI: 10.1016/j.toxicon.2014.02.008

Ferrer-González, B.M., García-Martínez, I. \& Totosaus, A., 2019. Textural properties, sensory acceptance and fatty acid profile of cooked meat batters employing pumpkin seed paste or soybean oil oleogel as fat replacers. Grasas Aceites 70, 320-331. DOI: 10.3989/gya.1055182

French, P., O'riordan, EG., Monahan, F.J., Caffreyb, P.J. \& Moloneya, A.P., 2003. Fatty acid composition of intramuscular triacylglycerols of steers fed autumn grass and concentrates. Livest. Prod. Sci., 81, 307-317. DOI: 10.1016/S0301-6226(02)00253-1 
Fonteles, N.L.O., Alves, S.P., Madruga, M.S., Queiroga, R.R.E., Andrade, A.P., Silva, D.S., Leal, A.P. Bessa, R.J.P. \& Medeiros, A.N., 2018. Fatty acid composition of polar and neutral meat lipids of goats browsing in native pasture of Brazilian semiarid. Meat Sci. 139, 149-156. DOI: 10.1016/j.meatsci.2018.01.021

Hamm, R., 1960. Biochemistry of meat hydration. Advances in Food Research, 10, 355-463. PMID: 13711042

Hopkins, D.L., Toohey, E.S., Warner, R.D., Kerr, M.J. \& Van de Ven, R., 2010. Measuring the shear force of lamb meat cooked from frozen samples, Comparison of two laboratories. Anim. Prod. Sci. 50, 382-385. DOI: 10.1071/AN09162

Joy, M., Ripoll, G. \& Delfa, R., 2008. Effects of feeding system on carcass and no-carcass composition of Churra Tensina light lambs. Small Ruminant Res., 78, 123-133. DOI: 10.1016/j.smallrumres.2008.05.011

Moloney, A.P., Kennedy, C., Noci, F., Monahan, F.J. \& Kerry, J.P., 2012. Lipid and colour stability of longissimus muscle from lambs fed camelina or linseed as oil or seeds. Meat Sci. 92, 1-7. DOI: https://doi.org/10.1016/j.meatsci.2012.03.011

Moreno, G.M.B., Lima Júnior, D.M., Souza, N.O.B., Cirne, L.G., Boaventura Neto, O. \& Souza, S.F., 2016. Quality of lamb meat: genotype and nutritional management. Ciên. Vet. Tróp., 19, 118-129.

Muela, E., Saudño, C., Campo, M.M., Medel, I. \& Beltrán, J.A., 2010. Effect of freezing method and frozen storage duration on instrumental quality of lamb throughout display. Meat Sci., 84, 662-669. DOI: 10.1016/j.meatsci.2009.10.028

Muela, E., Monge, P., Sañudo, C., Campo, M.M. \& Beltrán, J.A., 2016. Sensory quality of lamb following long-term frozen storage. Meat Sci., 114, 32 -37. DOI: 10.1016/j.meatsci.2015.12.001

Neethling, N.E., Suman, S.P., Sigge, G.O., Hoffman, L.C. \& Hunt, M.C., 2017. Exogenous and endogenous factors influencing color of fresh meat from ungulates. Meat Muscle Biol., 1, 253-275. DOI:10.22175/mmb2017.06.0032

Osório, J.C.S., Osório, M.T.M., Vargas Junior, F.M., Fernandes, A.R.M., Seno, L.O., ..., Orrico Junior, M.A.P., 2012. Criteria for animal slaughter and meat quality. Rev. Agrarian, 5, 433-443.

Osório, J.C.S., Osório, M.T.M. \& Sañudo, C., 2009. Sensory characteristics of ovine meat. Rev. Bras. Zoot., 38, $292-300$. DOI: http://dx.doi.org/10.1590/S1516-35982009001300029

Papi, N., Mostafa-Tehrani, A., Amanlou, H. \& Memariam, M., 2011. Effects of dietary forage-to-concentrate ratios on performance and carcass characteristics of growing fat-tailed lambs. Anim. Feed Sci. Technol. 163: 93-98. DOI: https://doi.org/10.1016/j.anifeedsci.2010.10.010

Pariza, M., Park, Y. \& Cook, M., 2001. The biologically active isomers of conjugated linoleic acid. Prog. Lipid. Res., 40, 283-298. DOI: 10.1016/S0163-7827(01)00008-X

Priolo, A., Micol, D., Agabriel, S., Prache, S. \& Dransfield, E., 2002. Effect of grass or concentrate feeding systems on lamb carcass and meat quality. Meat Sci., 62, 179-185. DOI: https://doi.org/10.1016/S0309-1740(01)00244-3

Pugh, D.G., 2004. Clínica de ovinos e caprinos. 1st ed. Roca, São Paulo 528 pp.

Rosa, H.J.D., Rego, O.A., Silva, C.C.G., Alves, S.P., Alfaia, C.M.M., Prates, J.A.M. \& Bessa, R.J.B., 2014. Effect of corn supplementation of grass finishing of Holstein bulls on fatty acid composition of meat lipids. J. Anim. Sci. 92, 3701-3714. DOI: 10.2527/jas.2013-6982

Ramos, E.M. \& Gomide, L.A.M., 2009. Meat quality assessment: Fundamentals and methodologies. 5th ed. Viçosa, Minas Gerais, Universidade Federal de Viçosa. 599 pp.

Rodrigues, S. \& Teixeira, A., 2009. Effect of sex and carcass weight on sensory quality of goat meat of Cabrito Transmontano. J. Anim. Sci., 87, 711-715. DOI: 10.2527/jas.2007-0792

Santos, J.R.S., Pereira Filho, J.M., Silva, A.M.A., Cezar, M.F., Borburema, J.B. \& Silva, J.O.R., 2009. Tissue and chemical composition of commercial carcass cuts of Santa Inês lambs finished in native pasture with supplementation. Rev. Bras. Zoot., 38, 2499-2505. DOI: 10.1590/S1516-35982009001200028

Sant'Ana, A.M.S., Bessa, R.J.B., Alves, S.P., Medeiros, A.N., Costa, R.G., .., Queiroga, R.C.R.E., 2018. Fatty acid, volatile and sensory profiles of milk and cheese from goats raised on native semiarid pasture or in confinement, Int. Dairy J., 91, 147-154. DOI: 10.1016/j.idairyj.2018.09.008

Scollan, N., Hocquette, J. F., Nuernberg, K., Dannenberger, D., Richardson, I. \& Moloney, A., 2006. Innovations in beef production systems that enhance the nutritional and health value of beef lipids and their relationship with meat quality. Meat Sci. 74(1), 17-33. DOI: 10.1016/j.meatsci.2006.05.002

Sousa, W.H., 2007. The agribusiness of the meat type goat in brazil. Rev. Tecnol. Ciên. Agropec., 1: 51-58.

Turner, K.E., Belesky, D.P., Cassida, K.A. \& Zerby, H.N., 2014. Carcass merit and meat quality in Suffolk lambs, Katahdin lambs, and meat-goat kids finished on a grass-legume pasture with and without supplementation. Meat Sci., 98, 211-219. DOI: 10.1016/j.meatsci.2014.06.002

Valsta, L.M., Tapanainen, H. \& Männistö, S., 2005. Meat fats in nutrition. Meat Sci., 70, 525-530. DOI: 10.1016/j.meatsci.2004

Vargas Junior, F.M., Socorro, M.M., Setti, J.C., Setti, J.D., Pinto, G.S., ..., Montagner, D.B., 2013. Availability and nutritive value of tropical grasses under grazing with sheep. Short comment. Rev. Arch. Zoot., 238, 295-298. DOI: https://doi.org/10.21071/az.v62i238.673

Vicini, L., 2005. Multivariate analysis of theory to practice. Universidade Federal de Santa Maria-UFSM, CCNE, Santa Maria. 215 pp.

Wood, J.D., Richardson, R.I., Nute, G.R., Fisher, A.V., Campo, M.M., ..., Enser, M., 2003. Effects of fatty acids on meat quality: A review. Meat Sci., 66, 21-32. DOI: 10.1016/S0309-1740(03)00022-6

Xue, H., Mainville, D., You, W. \& Nayga Jr, R.M., 2010. Consumer preferences and willingness to pay for grass-fed beef: Empirical evidence from in-store experiments. Food Qual. Prefer., 21: 857-866. DOI: https://doi.org/10.1016/j.foodqual.2010.05.004 
Zanini, G.D., Santos, G.T., Schmitt, D., Padilha, D.A. \& Sbrissia, A.F., 2012. Distribution of stem in the vertical structure of Aruana guinea grass and Annual ryegrass pastures subjected to rotational grazing by sheep. Ciênc. Rural, 42: 882-887.

Zeola, N.M.B.L., Souza, P.A., Souza, H.B.A., Silva Sobrinho, A.G. \& Barbosa, J.C., 2007. Evaluation of calcium chloride injection on the qualitative parameters of ewe meat. Arq. Bras. Med. Vet. Zoot., 59, 1058-1066. DOI: http://dx.doi.org/10.18539/cast.v11i3.1271 